\title{
Psychological distress among infectious disease physicians during the response to the COVID-19 outbreak in the Republic of Korea
}

Se Yoon Park ${ }^{1 \dagger}$, Bongyoung Kim² ${ }^{2 \dagger}$, Dong Sik Jung ${ }^{3}$, Sook In Jung ${ }^{4}$, Won Sup Oh${ }^{5}$, Shin-Woo Kim ${ }^{6}$, Kyong Ran Peck ${ }^{7}$ Hyun-Ha Chang ${ }^{6^{*}}$ (D) and The Korean Society of Infectious Diseases

\begin{abstract}
Background: This study aimed to investigate psychological distress among infectious disease (ID) physicians during the coronavirus disease 2019 (COVID-19) outbreak in the Republic of Korea.

Methods: Using an online-based survey link sent via text message and email, we conducted a survey from April 21 to 25,2020 , targeting all ID physicians currently working in ID $(n=265)$. The questionnaire was based on the Maslach Burnout Inventory-Human Services Survey and the Depression, Anxiety, and Stress Scales, and information was collected on factors protecting against psychological distress and difficulties in relation to COVID-19.

Results: Of 265 ID physicians, 115 (43.3\%) responded, showing burnout (97, 90.4\%), depression (20, 17.4\%), anxiety $(23,20.0 \%)$, and stress $(5,4.3 \%)$. There were no differences in terms of distress between ID physicians who were directly involved in the care of patients with COVID-19 or not. Greater than 50\% of physicians valued their work and felt recognized by others, whereas $<10 \%$ indicated that sufficient human and financial support and private time had been provided during the outbreak. The most challenging issues concerned a lack of attending physicians caring for COVID-19 patients or infection control practitioners, a shortage of personal protective equipment or airborne infection isolation rooms, pressure for research, and lack of guidelines for COVID-19 management.

Conclusions: During the COVID-19 outbreak in the Republic of Korea, most respondents reported psychological distress. Preparing strategies to secure human resources are crucial to prepare effectively for future epidemics and pandemics.
\end{abstract}

Keywords: COVID-19, Infectious diseases medicine, Burnout, Psychological, Psychological distress, South Korea

\footnotetext{
*Correspondence: changhha@knu.ac.kr

tSe Yoon Park, and Bongyoung Kim are contributed equally to this work as co-first authors.

${ }^{6}$ Division of Infectious Diseases, Department of Internal Medicine, School of Medicine, Kyungpook National University, 130 Dongdeok-ro, Daegu, Jung-gu 41944, South Korea

Full list of author information is available at the end of the article
}

(c) The Author(s). 2020 Open Access This article is licensed under a Creative Commons Attribution 4.0 International License, which permits use, sharing, adaptation, distribution and reproduction in any medium or format, as long as you give appropriate credit to the original author(s) and the source, provide a link to the Creative Commons licence, and indicate if changes were made. The images or other third party material in this article are included in the article's Creative Commons licence, unless indicated otherwise in a credit line to the material. If material is not included in the article's Creative Commons licence and your intended use is not permitted by statutory regulation or exceeds the permitted use, you will need to obtain permission directly from the copyright holder. To view a copy of this licence, visit http://creativecommons.org/licenses/by/4.0/ The Creative Commons Public Domain Dedication waiver (http://creativecommons.org/publicdomain/zero/1.0/) applies to the data made available in this article, unless otherwise stated in a credit line to the data. 


\section{Background}

An infectious diseases (ID) physician has an important role when dealing with emerging diseases such as coronavirus disease 2019 (COVID-19). ID physicians have a combined role in participating in patient care and providing advice based on scientific evidence for prevention strategies to each medical institution and government [1]. Since the 2000s, the Republic of Korea (ROK) has experienced several ID outbreaks, including the H1N1 influenza pandemic in 2009 and the Middle East respiratory syndrome (MERS) outbreak in 2015 [1, 2].

The first case of COVID-19 in the ROK was diagnosed in a person who entered from Wuhan, China, in January 2020 and, since then, the ROK has been combatting the COVID-19 pandemic. A large-scale outbreak occurred in Daegu and surrounding areas that was linked to a religious event held in mid-February, followed by several smaller outbreaks throughout the ROK and, by the end of April 2020, a total of 10,752 patients with COVID-19 had been confirmed, along with 244 COVID-19-related deaths [3].

In response to the COVID-19 outbreak that has continued for more than three months, the psychological effects of this outbreak on medical staff has been analyzed in several countries $[4,5]$. However, there has been no analysis of the psychological effects on ID physicians, specifically, specialists who have played a pivotal role in responding to the COVID-19 outbreak in many countries, including the ROK. This study aimed to analyze the extent of psychological distress among ID physicians in the ROK during the COVID-19 outbreak. Moreover, we aimed to investigate factors protecting against psychological distress and the difficulties facing ID physicians when dealing with the COVID-19 outbreak to determine their specific work-related requirements.

\section{Methods}

\section{Study design and population}

This study used a cross-sectional quantitative design. A survey was conducted over a 5-day period, from April 21 to 25 , 2020, targeting all ID physicians in the ROK $(n=$ 275). At the time of the survey, 10 ID physicians were identified as either having retired or died and were excluded. In total, 265 ID physicians were identified as potential participants in the survey and an online-based survey link was forwarded to them via text messaging and e-mail. No financial incentive was offered for completion of the questionnaire. The respondents were anonymized and were requested to enter their own identification number to distinguish any duplicated answers. The study protocol was approved by the Institutional Review Board (IRB) of Soonchunhyang University Seoul Hospital. Written informed consent was obtained from participants via their online participation.

\section{Survey items}

The questionnaire was based on the Maslach Burnout Inventory-Human Services Survey (MBI-HSS) and the Depression, Anxiety, and Stress Scales (DASS-21). The MBI-HSS is used to assess emotional exhaustion, depersonalization, and lack of personal accomplishment. The license provided by Mind Garden ${ }^{\circledR}$ was obtained for the use of the Maslach Burnout Inventory. Summed scores are compared with standardized thresholds set out in the MBI-HSS manual (cutoff scores: $>22$ for emotional exhaustion, $>7$ for depersonalization, $<36$ for personal accomplishment) [6]. Overall burnout is defined as a high score in either the emotional exhaustion or depersonalization subscale [7]. The DASS-21 is a 21item system that provides independent measures of depression, stress, and anxiety with recommended severity thresholds. Cutoff scores $>9,>7$, and $>14$ indicate a positive screen for depression, anxiety, and stress, respectively [8].

We investigated factors protecting against psychological distress among ID physicians. We used a survey item with a 5-point Likert scale by modifying questions of the ID Burnout Inventory from a previous study [7] and divided the questionnaire into four categories, as follows: (1) value of work and recognition from others, (2) human and financial support, (3) housework and childcare, and (4) ensuring sufficient private time. We also investigated difficulties experienced by ID physicians when responding to the COVID-19 outbreak. A respondent could select up to three items among 11 items concerning difficulties they had been experiencing (see the questionnaire in Supplementary).

\section{Statistical analysis}

SPSS version 24.0 for Windows (IBM; Armonk, NY) was used for statistical analysis. Chi-squared or Fisher's exact tests were used to compare categorical variables, and Student's t-test was used for continuous variables. Variables with a $P$-value $<0.05$ were considered statistically significant.

\section{Results}

\section{Baseline characteristics of the ID physicians}

Of 265 surveys, we received 115 (43.3\%) responses. The respondents' characteristics are shown in Table 1 . All respondents were working in hospitals; 53 (46.1\%) and 48 (41.7\%) respondents were working as Directors of ID Departments or as Directors of an Infection Control team, respectively. The median number of years spent working as a Director of an Infection Control team was 5 years (interquartile range [IQR], 3-13 years). COVID19 -related work was reported to comprise $>80 \%$ of total workload for $23(20.0 \%)$ and 67 (58.3\%) respondents for the last two weeks and the busiest week of the COVID- 
Table 1 Baseline characteristics of the ID physicians

\begin{tabular}{|c|c|c|c|c|}
\hline \multirow[t]{2}{*}{ Characteristics } & \multirow{2}{*}{$\begin{array}{l}\text { Total, } \\
n=115 \text { (\%) }\end{array}$} & \multicolumn{2}{|c|}{ COVID-19 patient care } & \multirow[t]{2}{*}{$P$-value } \\
\hline & & Yes $(n=78)$ & No $(n=37)$ & \\
\hline Sex, Female & $67(58.3)$ & $43(55.1)$ & $24(64.9)$ & 0.323 \\
\hline Age, median (IQR), years & $41(37-48)$ & $42(37-48)$ & $41(38-47)$ & 0.904 \\
\hline \multicolumn{5}{|l|}{ Marital status } \\
\hline Married & $94(81.7)$ & $66(84.6)$ & $28(75.7)$ & 0.246 \\
\hline Have children & $86(74.8)$ & $62(79.5)$ & $24(64.9)$ & 0.092 \\
\hline \multicolumn{5}{|l|}{ Position in hospital } \\
\hline Director of an ID department & $53(46.1)$ & $33(42.3)$ & $20(54.1)$ & 0.238 \\
\hline Director of an Infection Control team & $48(41.7)$ & $28(35.9)$ & $20(54.1)$ & 0.065 \\
\hline Both & $30(26.1)$ & $13(16.7)$ & $17(45.9)$ & 0.001 \\
\hline Numbers of ID specialists in the hospital, median (IQR) & $3(2-4)$ & $3(2-4)$ & $2(1-3)$ & 0.194 \\
\hline Length of career as an ID specialist (IQR), years & $8(4-13)$ & $9(3-13)$ & $7(4-14)$ & 0.817 \\
\hline Type of hospital & & & & $<0.001$ \\
\hline University-affiliated hospital & $86(74.8)$ & $65(83.3)$ & $21(56.8)$ & \\
\hline Private, non-university-affiliated hospital & $19(16.5)$ & $5(6.4)$ & $15(40.5)$ & \\
\hline Public, non-university-affiliated hospital & $9(7.8)$ & $8(10.3)$ & $1(2.7)$ & \\
\hline Number of hospital beds & & & & $<0.001$ \\
\hline$\geq 1200$ & $22(19.1)$ & $16(20.5)$ & $6(16.2)$ & \\
\hline $900-1200$ & $21(18.3)$ & $21(26.9)$ & 0 & \\
\hline $600-900$ & $45(39.1)$ & $29(37.2)$ & $16(43.2)$ & \\
\hline $300-600$ & $24(20.9)$ & $12(15.4)$ & $12(32.4)$ & \\
\hline$<300$ & $3(2.6)$ & 0 & $3(8.1)$ & \\
\hline Participation in COVID-19 related night duty & $68(59.1)$ & $56(71.8)$ & $12(32.4)$ & $<0.001$ \\
\hline \multicolumn{5}{|l|}{ Working hours per week } \\
\hline Recent 2 weeks (April 2020), median (IQR), h & $62(50-74)$ & $65(54-76)$ & $52(45-62)$ & $<0.001$ \\
\hline During COVID-19 outbreak, median (IQR), h & $84(66-102)$ & $90(75-115)$ & $70(53-84)$ & $<0.001$ \\
\hline
\end{tabular}

Abbreviations: COVID-19 coronavirus disease-19, ID infectious disease, IQR interquartile range

19 outbreak, respectively. The mean number of weekly working hours was $62 \mathrm{~h}$ in April 2020 and 84h during the busiest week of the COVID-19 outbreak. The ID physicians who were treating patients with COVID-19 worked significantly longer $(P<0.001)$.

\section{Results concerning the psychological effects of COVID-19} Ninety-seven (90.4\%) respondents screened positive for burnout, 20 (17.4\%) for depression, $23(20.0 \%)$ for anxiety, and five $(4.3 \%)$ for stress (Table 2). There was no difference among ID physicians who cared for patients with or without COVID-19 (Table 2). Prevalence rates for burnout were similar between the sexes. Female ID physicians tended to report depression, anxiety, and stress more frequently than their male counterparts, and a higher proportion of female ID physicians were found to endorse emotional exhaustion (Supplemental Table 1).

Forty-six $(40 \%)$ respondents reported that they were satisfied working as ID physicians, whereas 26 (22.6\%) reported they were not satisfied. When asked if they would choose an ID specialty if they could choose their specialty again, 46 (40\%) responded positively and 36 (31.3\%) responded negatively. Sixty-seven (76\%) respondents reported a sense of responsibility and pride in performing COVID-19-related tasks, whereas nine (6.1\%) did not (Fig. 1). In female ID physicians, satisfaction was significantly lower than that in male ID physicians $(32.8 \%$ vs. $50 \%, p=0.018)$. There was no difference in re-selection of an ID specialty (31.1\% vs. $52.1 \%, p=$ $0.072)$ or pride and responsibility $(67.2 \%$ vs. $64.2 \%, p=$ $0.018)$.

\section{Factors protecting against psychological distress}

More than $50 \%$ of respondents reported that their work was valued and that it had been recognized by others. Less than $20 \%$ of ID physicians reported that they had sufficient human or financial support (in terms of adequate staff [16.5\%], financial compensation [9.6\%], work-life balance [8.7\%], and adequate coverage of responsibility [7.8\%]), and sufficient private time (i.e., 
Table 2 Prevalence of depression, anxiety, stress, burnout and mean DASS-21/MBI-HSS scores according to care of patients with COVID-19

\begin{tabular}{|c|c|c|c|c|c|c|c|}
\hline \multirow[t]{2}{*}{ Outcome } & \multicolumn{2}{|c|}{ Total $(n=115)$} & \multicolumn{2}{|c|}{$\begin{array}{l}\text { COVID-19 patient care, Yes } \\
(n=78)\end{array}$} & \multicolumn{2}{|c|}{ COVID-19 patient care, No $(n=37)$} & \multirow[t]{2}{*}{$P$-value } \\
\hline & $\begin{array}{l}\text { Prevalence, } \\
n(\%)\end{array}$ & $\begin{array}{l}\text { Score, mean } \\
\pm \text { SD }\end{array}$ & $\begin{array}{l}\text { Prevalence, } \\
n(\%)\end{array}$ & $\begin{array}{l}\text { Score, mean } \\
\pm S D\end{array}$ & $\begin{array}{l}\text { Prevalence, } \\
n(\%)\end{array}$ & $\begin{array}{l}\text { Score, mean } \\
\pm \text { SD }\end{array}$ & \\
\hline \multicolumn{8}{|l|}{ DASS-21 } \\
\hline Depression & $20(17.4)$ & $5.45 \pm 4.16$ & $14(17.9)$ & $5.58 \pm 4.30$ & $6(16.2)$ & $5.19 \pm 3.90$ & 0.643 \\
\hline Anxiety & $23(20.0)$ & $3.88 \pm 3.74$ & $17(21.8)$ & $3.85 \pm 3.63$ & $6(16.2)$ & $3.95 \pm 4.01$ & 0.894 \\
\hline Stress & $5(4.3)$ & $6.23 \pm 3.86$ & $4(5.1)$ & $6.21 \pm 3.94$ & $1(2.7)$ & $6.30 \pm 3.75$ & 0.905 \\
\hline \multicolumn{8}{|l|}{ MBI-HSS scale } \\
\hline Emotional exhaustion & $97(84.3)$ & $34.92 \pm 10.01$ & $68(87.2)$ & $35.96 \pm 10.32$ & $29(78.4)$ & $32.73 \pm 9.25$ & 0.108 \\
\hline Depersonalization & $76(66.1)$ & $10.55 \pm 5.69$ & $51(65.4)$ & $10.71 \pm 6.01$ & $25(67.6)$ & $10.22 \pm 5.01$ & 0.669 \\
\hline Personal accomplishments & $76(66.1)$ & $31.66 \pm 8.18$ & $51(65.4)$ & $32.21 \pm 8.54$ & $25(67.6)$ & $30.51 \pm 7.34$ & 0.302 \\
\hline Burnout & $104(90.4)$ & NA & $71(91.0)$ & NA & $33(89.2)$ & NA & 0.774 \\
\hline
\end{tabular}

Abbreviations: DASS-21 Depression, Anxiety, and Stress scale-21, MBI-HSS the Maslach Burnout Inventory-Human Services Survey, NA not available, SD standard deviation

working at home was not required [2.6\%] and they had enough time to enjoy leisure activities and time spent at home [2.6\%]). Only $33 \%$ of respondents reported sharing household responsibilities equally with their spouse/ partner and $15.7 \%$ of respondents reported that childcare was not a significant source of stress for them (Table 3).

\section{Difficulties in responding to the COVID-19 outbreak}

ID physicians most commonly reported difficulties derived from a lack of healthcare workers and infection control practitioners, followed by a lack of personal protective equipment (PPE), airborne-infection isolation rooms (AIIRs), research support (responsibility, multicenter opportunities, and strict IRB requirements), as well as guidelines for COVID-19-related care and PPE reuse (Fig. 2).

\section{Discussion}

During the COVID-19 outbreak, the prevalence rate of burnout among the ID physicians in the ROK responding to our survey was $90.4 \%$. There have been inconsistencies in defining burnout and in the assessment methods used to identify burnout across studies; however, our results showed higher burnout than those of a previous meta-analysis involving physicians, which reported a burnout range from 0 to $80.5 \%$ [9]. Compared to studies conducted in 1992 and in 2008 in the United States involving ID physicians that reported burnout levels of $40-50 \%$, the prevalence of burnout in our study was considerably higher $[7,10]$. Our results showed that ID physicians experienced burnout more during the COVID-19 outbreak. One study, undertaken during the COVID-19 pandemic at an oncology ward in Wuhan, China, reported the prevalence of burnout among oncology physicians and nurses was $26 \%$. Unexpectedly, the

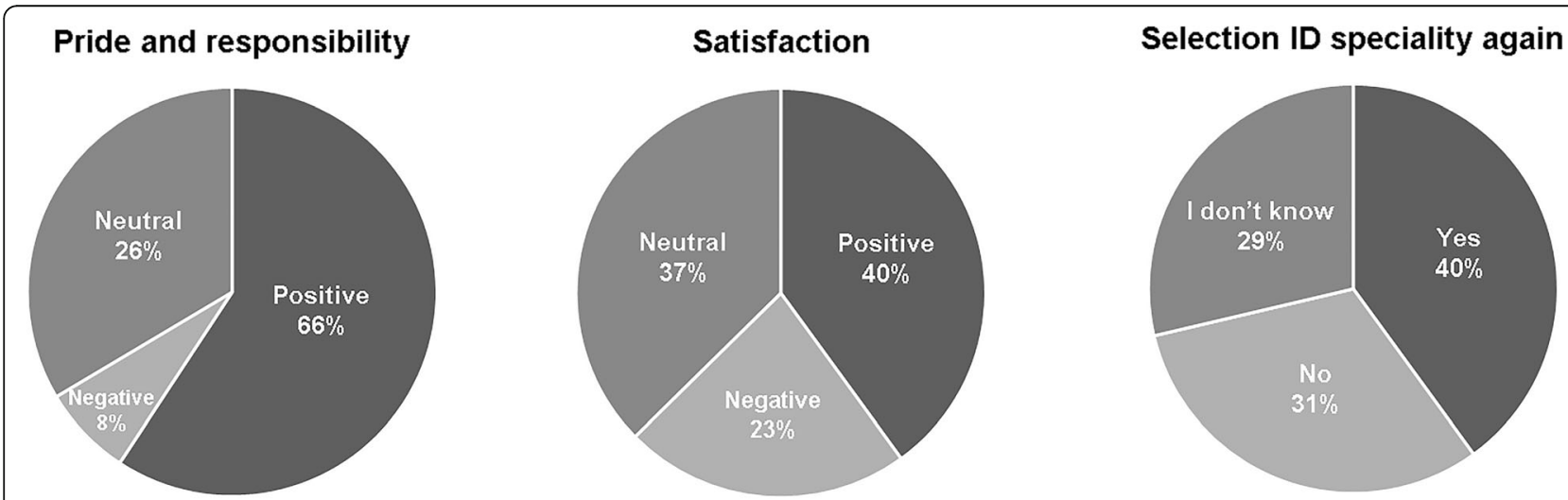

Fig. 1 Pride and responsibility, and satisfaction as an infectious disease physician, and intention to select infectious disease specialty again if responders were to have another opportunity to choose a specialty 
Table 3 Factors protective against burnout as an ID physician

\begin{tabular}{|c|c|}
\hline Categories & Total $n=115, n(\%)$ \\
\hline \multicolumn{2}{|l|}{ Value of work and recognition from others } \\
\hline I feel my professional opinions are valued by other physicians & $102(88.7)$ \\
\hline I feel that my spouse or partner values my work & $81(70.4)$ \\
\hline I feel that my career is a large part of my identity as an adult & $80(69.6)$ \\
\hline I feel that my contributions are adequately recognized and acknowledged by my supervisors & $67(58.3)$ \\
\hline \multicolumn{2}{|l|}{ Human and financial support } \\
\hline I feel that I have adequate support staff for maximum productivity in this role & $19(16.5)$ \\
\hline I feel that I am adequately financially compensated for my work & $11(9.6)$ \\
\hline I feel that it is possible to balance work and non-work responsibilities & $10(8.7)$ \\
\hline I feel that I have adequate coverage of my work responsibilities to tend to personal matters, emergencies, illness, etc. & $9(7.8)$ \\
\hline \multicolumn{2}{|l|}{ Housework and childcare } \\
\hline My spouse/partner and I try our best to share household responsibilities equally & $38(33)$ \\
\hline Childcare is not a significant source of stress for me & $18(15.7)$ \\
\hline \multicolumn{2}{|l|}{ Ensuring enough private time } \\
\hline I do not often have to complete work at home (clinician, infection control, and research) & $3(2.6)$ \\
\hline I have enough time to do something I enjoy & $3(2.6)$ \\
\hline
\end{tabular}

prevalence was significantly lower for frontline medical personnel than for those working in the oncology ward [5]. In our study, direct COVID-19 patient care resulted in long working hours and night duty; however, the frequency of burnout and the levels of depression, anxiety, and stress did not differ significantly between ID physicians who cared for patients with COVID-19 and those who did not. Moreover, female ID physicians were found to report a significantly higher frequency of psychological issues in depression, anxiety, stress, and emotional exhaustion compared to males. It is possible that they may be at risk because of undertaking greater responsibilities for childcare and household duties due to social changes occurring at the start of the pandemic, such as the closure of schools and delays in their reopening.

In November 2019, there were 255 ID physicians working in the ROK, who comprised only $3.2 \%$ of subspecialized internal medicine doctors. The number of ID physicians was 0.5 per 100,000 people, which is a lower ratio than the number of ID physicians working in the United States (2.8 per 100,000 people) [11]. ID physicians play an important role not only in the outbreak response to COVID-19 but also in direct patient care, infection control, antibiotic stewardship, education, disease surveillance, and outpatient antibiotic therapy $[12,13]$. Concerning patient care,

\section{Difficulties in response to the COVID-19 outbreak}

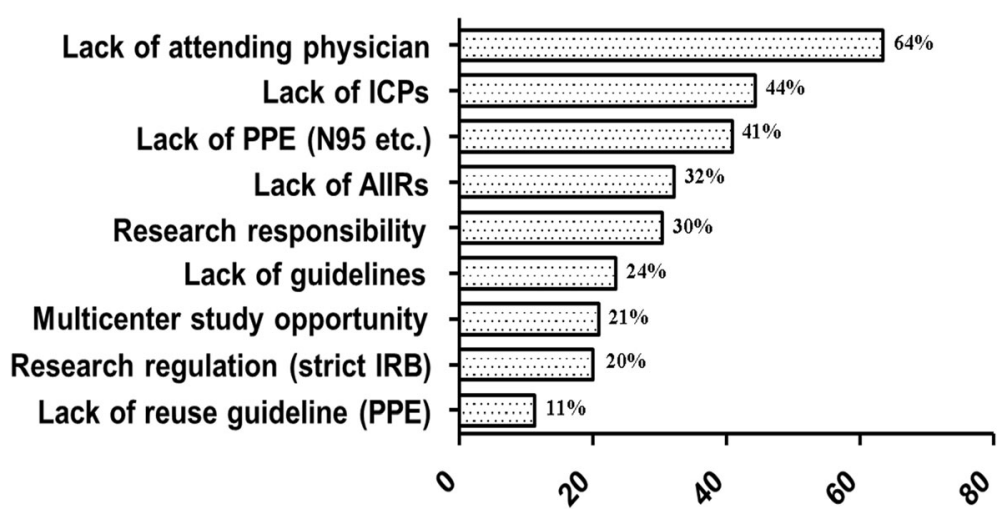

Fig. 2 Difficulties in response to the COVID-19 outbreak. Abbreviations: COVID-19, coronavirus disease 19; ICPs, infection control practitioners; PPE, personal protective equipment, AllRs, airborne infection isolation rooms; IRB, Institutional Review Board 
intervention by ID physicians has been reported to be significantly associated with lower mortality rates, shorter hospital stays, and reduced healthcare costs [14, 15]. Many studies have shown that consultation with ID physicians can optimize antibiotic prescription [16, 17]. In a study conducted in a large Korean hospital, one ID specialist-led antimicrobial stewardship program concerning antibiotic use resulted in a meaningful reduction in antibiotic use and a decrease in the antibiotic resistance rate without changing the mortality rate [17]. However, despite the proven efficacy of ID physician intervention, much of their work has been reported to be undercompensated [18].

During the COVID-19 outbreak, most respondents felt valued in their work and had been recognized by others. However, $>90 \%$ of respondents considered that there was a shortage of adequate staff and inadequate financial compensation. Supporting medical staff and infection control practitioners who directly care for patients with COVID-19 was found to be a more urgent requirement than dealing with issues arising due to a lack of PPE or AIIRs. All respondents were working in hospitals, and more than two-thirds worked in university-affiliated hospitals. Furthermore, $>40 \%$ of the ID physicians were ID Department Directors or Directors of an Infection Control team. Our results showed that most ID physicians in the ROK played various roles, not only in terms of patient care but also in infection control, administration, education, and research.

The ROK experienced a MERS outbreak in 2015; however, only approximately 50 ID physicians had been subsequently trained by 2020 , with only 10 applicants for the ID specialty annually (data not shown). During an infectious disease crisis, ID physicians have acted as coordinators and have been at the forefront of the response to the outbreak and in providing patient care, but they have been reported to be inadequately compensated by relevant institutions or governments [1]. This latter factor may have led to fewer applicants for the role of ID physician or as ICP. A shortage of ID physicians is likely to require greater participation in various duties related to caring for confirmed patients with COVID-19 and in infection control with a more demanding workload, resulting in a higher likelihood of psychological distress such as burnout, depression, anxiety, and stress.

In the survey, only $40 \%$ of the ID physicians responded that they were satisfied with their work and that they would select to be an ID physician again if they had another chance to choose their specialty. However, $76 \%$ of the respondents indicated they felt a sense of responsibility and pride in their work in combatting COVID-19. In particular, female ID physicians were found to have significantly lower satisfaction than males. This may also be related to the psychological distress reported as experienced by female ID physicians, which was worse than that reported for their male colleagues. One Korean study of gastrointestinal physicians highlighted a worklife imbalance, and burnout was found to be most severe among young female gastrointestinal physicians due to additional pressure to address domestic requirements [19]. In our study, this factor could also be a possible explanation for differences between male and female ID physicians, as female ID physicians reported feeling considerably more pressure than male ID physicians in terms of childcare commitments. Further research is needed to confirm whether this factor is important in relation to ID physicians. In addition, this apparent sex difference needs to be re-evaluated outside of the COVID-19 outbreak.

This study had some limitations. As only ID physicians were surveyed, it would be difficult to draw conclusions in terms of other specialties. Further, the response rate was only $43.3 \%$, and the responses obtained may not be accurately representative of the ID physician population. Because of the relatively short response time, it is possible that busy respondents could not answer. However, it would have been challenging to attain a higher response rate, despite the survey time having been extended for $>5$ days, because of the reality of time constraints and high workload volumes due to the COVID-19 outbreak during this survey period.

\section{Conclusions}

The findings of our study showed that the COVID-19 outbreak imposed considerable psychological distress on ID physicians and that greater numbers of ID physicians and support staff were needed for patient care and infection control. Strategies to secure human resources are crucial to prepare effectively for future epidemics and pandemics.

\section{Supplementary Information}

The online version contains supplementary material available at https://doi. org/10.1186/s12889-020-09886-w.

Additional file 1: Supplemental Table 1. Prevalence of depression, anxiety, stress, burnout and mean DASS-21/MBI-HSS scale according to sex.

\section{Abbreviations}

ID: Infectious diseases; COVID-19: Coronavirus disease 2019; ROK: Republic of Korea; MERS: Middle East respiratory syndrome; IRB: Institutional Review Board; MBI-HSS: Maslach Burnout Inventory-Human Services Survey; DASS21: Depression, Anxiety, and Stress Scales; IQR: Interquartile range;

PPE: Personal protective equipment; AlIRs: Airborne-infection isolation rooms

\section{Acknowledgements}

We would like to acknowledge all the respondents for their participation in the survey. The authors are also grateful to the Korean Society of Infectious Disease for identifying the target participants for the survey. 


\section{Authors' contributions}

SYP, BK, and H-HC developed the study design. SYP, BK, and H-HC were responsible for data collection. SYP, BK, DSJ, SIJ, SWK, KRP, and H-HC assisted with data interpretation. SYP performed the literature search and wrote the first draft of the paper. SYP obtained funding for the study. BK, DSJ, SIJ, SWK, $\mathrm{KRP}$, and $\mathrm{H}-\mathrm{HC}$ have critically read and commented on draft versions of the report. All authors have read and approved the final manuscript.

\section{Funding}

This work was supported by the National Research Foundation of Korea (NRF) grant funded by the Korea government (MSIT)(No.

2019R1G1A1099867) and Soonchunhyang University Research Fund. The funding body had no role in study design, data collection and analysis, interpretation of data, or preparation of the manuscript.

\section{Availability of data and materials}

The analysis data is not available as it contains protected personal information. An anonymized data set is not available upon request.

\section{Ethics approval and consent to participate}

The study protocol was approved by the Institutional Review Board (IRB) of Soonchunhyang University Seoul Hospital (IRB number: 2020-04-024). Written informed consent was obtained from participants via their online participation.

\section{Consent for publication}

Not applicable: this manuscript does not contain any personal data from participants.

\section{Competing interests}

The authors declare that they have no completing interests.

\section{Author details}

'Division of Infectious Diseases, Department of Internal Medicine, Soonchunhyang University Seoul Hospital, Soonchunhyang University College of Medicine, Seoul, Republic of Korea. ${ }^{2}$ Department of Internal Medicine, Hanyang University College of Medicine, Seoul, Republic of Korea. ${ }^{3}$ Division of Infectious Diseases, Department of Internal Medicine, Dong-A University College of Medicine, Busan, Republic of Korea. ${ }^{4}$ Department of Infectious Diseases, Chonnam National University Medical School, Gwangju, Republic of Korea. ${ }^{5}$ Division of Infectious Diseases, Department of Internal Medicine, Kangwon National University Hospital, Kangwon National University School of Medicine, Chuncheon, Republic of Korea. ${ }^{6}$ Division of Infectious Diseases, Department of Internal Medicine, School of Medicine, Kyungpook National University, 130 Dongdeok-ro, Daegu, Jung-gu 41944 South Korea. ${ }^{7}$ Division of Infectious Diseases, Samsung Medical Center, Sungkyunkwan University School of Medicine, Seoul, Republic of Korea.

Received: 19 June 2020 Accepted: 12 November 2020 Published online: 27 November 2020

\section{References}

1. Lee J, Kim WJ, Yoon HJ, Choi JY, Kim TH, Choi YH, et al. Collaborative intervention of middle east respiratory syndrome: rapid response team. Infect Chemother. 2016;48(2):71-4.

2. Choi WS, Kang C-I, Kim Y, Choi J-P, Joh JS, Shin H-S, et al. Clinical presentation and outcomes of Middle East respiratory syndrome in the Republic of Korea. Infect Chemother. 2016;48(2):118-26.

3. Updates of COVID-19 in Republic of Korea. Korea Centers for Disease Control and Prevention. 2020. http://ncov.mohw.go.kr/en/tcmBoardView. do?brdld=12\&brdGubun=125\&dataGubun=\&ncvContSeq=2087\&contSeq= 2087\&board_id=\&gubun=.

4. Tan BYQ, Chew NWS, Lee GKH, Jing M, Goh Y, Yeo LLL, et al. Psychological impact of the COVID-19 pandemic on health Care Workers in Singapore. Ann Intern Med. 2020;173(4):317-20.

5. Wu Y, Wang J, Luo C, Hu S, Lin X, Anderson AE, et al. A comparison of burnout frequency among oncology physicians and nurses working on the frontline and usual wards during the COVID-19 epidemic in Wuhan, China. J Pain Symptom Manage. 2020;60(1):e60-5.
6. Maslach C, Jackson SE, Michael P. Leiter. Maslach Burnout Inventory Manual. 4th ed. https://www.mindgarden.com/maslach-burnout-inventory-mbi/686mbi-manual-print.html.

7. Nori P, Bartash R, Cowman K, Dackis M, Pirofski LA. Is burnout infectious? Understanding drivers of burnout and job satisfaction among academic infectious diseases physicians. Open Forum Infect Dis. 2019;6(4):ofz092.

8. Lovibond SH, Lovibond PF. Manual for the depression anxiety stress scales. Sydney: Psychology Foundation of Australia; C1995.

9. Rotenstein LS, Torre M, Ramos MA, Rosales RC, Guille C, Sen S, et al. Prevalence of burnout among physicians a systematic review. JAMA - J Am Med Assoc. 2018;320(11):1131-50.

10. Deckard GJ, Hicks LL, Hamory BH. The occurrence and distribution of burnout among infectious diseases physicians. J Infect Dis. 1992;165(2):2248.

11. Physician Specialty Data Report. Association of American Medical Colleges. 2018. https:/www.aamc.org/data-reports/workforce/data/2018-physicianspecialty-data-report-executive-summary.

12. Petrak RM, Sexton DJ, Butera ML, Tenenbaum MJ, MacGregor MC, Schmidt ME, et al. The Value of an Infectious Diseases Specialist. Clin Infect Dis. 2003; 36(8):1013-7.

13. Brouqui $P$, Jouve $E$, Romain F, Sambuc R, Raoult D. Are infectious disease doctors better at caring for infectious diseases than other specialists? Clin Infect Dis. 2014;58(10):1486-7.

14. Schmitt S, McQuillen DP, Nahass R, Martinelli L, Rubin M, Schwebke K, et al. Infectious diseases specialty intervention is associated with decreased mortality and lower healthcare costs. Clin Infect Dis. 2014;58(1):22-8.

15. Schmitt S, Macintyre AT, Bleasdale SC, Ritter JT, Nelson SB, Berbari EF, et al. Early infectious diseases specialty intervention is associated with shorter hospital stays and lower readmission rates: a retrospective cohort study. Clin Infect Dis. 2019;68(2):239-46.

16. Rieg S, Küpper MF. Infectious diseases consultations can make the difference: a brief review and a plea for more infectious diseases specialists in Germany. Infection. 2016;44(2):159-66.

17. Hwang H, Kim B. Impact of an infectious diseases specialist-led antimicrobial stewardship programmes on antibiotic use and antimicrobial resistance in a large Korean hospital. Sci Rep. 2018:8(1):14757.

18. Zahn M, Adalja AA, Auwaerter PG, Edelson PJ, Hansen GR, Hynes NA, et al. Infectious diseases physicians: improving and protecting the public's health: why equitable compensation is critical. Clin Infect Dis. 2019;69(2):352-6.

19. 19. Jang ES, Park SM, Park YS, Lee JC, Kim N. Work-Life Conflict and Its Health Effects on Korean Gastroenterologists According to Age and Sex. Dig Dis Sci. 2020;65(1):86-95.

\section{Publisher's Note}

Springer Nature remains neutral with regard to jurisdictional claims in published maps and institutional affiliations.
Ready to submit your research? Choose BMC and benefit from:

- fast, convenient online submission

- thorough peer review by experienced researchers in your field

- rapid publication on acceptance

- support for research data, including large and complex data types

- gold Open Access which fosters wider collaboration and increased citations

- maximum visibility for your research: over $100 \mathrm{M}$ website views per year

At BMC, research is always in progress.

Learn more biomedcentral.com/submissions 